\title{
Measurement of Aerosol Parameters with Altitude by Using Two Wavelength Rotational Raman Signals
}

\author{
Imkang Song and Yonggi Kim \\ Department of Physics, Kongju National University, Gongju 314-701, Korea \\ Sung-Hoon Baik, Seung-Kyu Park, Hyungki Cha, Sungchul Choi, and Chin-Man Chung \\ Laboratory for Quantum Optics, Korea Atomic Energy Research Institute, Daejeon 305-353, Korea \\ Dukhyeon Kim* \\ Division of Cultural Studies, Hanbat National University, Daejoen 305-719, Korea
}

(Received July 2, 2010 : revised August 25, 2010 : accepted August 30, 2010)

\begin{abstract}
Aerosol size distribution provides good information for predicting weather changes and understanding cloud formation. Aerosol extinction coefficient and backscattering coefficient are measured by many scientists, but these parameters depend not only on aerosol size but on aerosol concentrations. An algorithm has been developed to measure aerosol parameters such as Ångström exponent, color ratio, and LIDAR ratio without any assumptions by using two wavelength rotational Raman LIDAR signals. These parameters are good indicators for the aerosol size. And we can find Ångström exponent, color ratio, and LIDAR ratio under various weather conditions. Finally, it can be seen that the Ångström exponent has an inverse relationship to the particle size of the aerosol and the color ratio is linearly dependent on the aerosol size. An Ångström exponent from 1.2 to 3.1, a color ratio from 0.28 to 1.04, and a LIDAR ratio 66.9 sr at $355 \mathrm{~nm}$ and $32.6 \mathrm{sr}$ at $532 \mathrm{~nm}$ near the cloud were obtained.
\end{abstract}

Keywords: LIDAR, Rotational Raman, Backscattering, Extinction, Color ratio

OCIS codes : (280.3640) Lidar; (290.5860) Rotational Raman; (290.1350) Backscattering; (290.2200) Extinction; (010.1100) Aerosol detection

\section{INTRODUCTION}

Optical properties of an atmospheric aerosol are very important parameters for predicting climate change. An aerosol has an indirect effect on the radiation budget of atmosphere providing condensation nuclei for cloud formation, because scattering and absorption of solar radiation and longwave radiation are dependent on atmospheric aerosol particle concentration, position, orientation, shape, and size. Sometimes the specific aerosol, Asian dust, impacts the Korean Peninsula or travels through the sky on the prevailing westerlies in varying degrees[1]. The occurrence rate of Asian dust has been rapidly increasing in the 2000s, and this specific Asian dust also affects the climate.

If there is fog, visibility is strongly dependent on the amount and size of water droplets. So, to predict weather changes, water droplet size change and other parameters such as temperature must be measured. Moreover, the aerosol backscattering coefficient and extinction coefficient cannot give enough information for identifying weather changes, so it is necessary to measure other parameters which are connected with aerosol size, such as Ångström exponent, color ratio, and LIDAR ratio[2, 3].

Many scientists have tried to measure simple aerosol properties such as backscattering coefficient, and extinction coefficient[4-6]. Moreover, they have obtained these backscattering and extinction coefficients with some assumptions such as Ångström exponent, color ratio, and LIDAR ratio[6, 7]. The Ångström exponent, $k$, value is 4 for molecules and varies between 0 and 2 for particles by the

\footnotetext{
*Corresponding author: dhkim7575@paran.com

Color versions of one or more of the figures in this paper are available online.
} 
Ångström's empirical formular $\alpha \propto \lambda^{-k}[8]$. This assumption causes systematic errors, because the Angström exponent of an aerosol is dependent on the type and size of the aerosol. The high spectral resolution LIDAR system does not need any of these assumptions, but the high spectral resolution LIDAR requires an expensive optics and laser system to separate the Mie scattering signal from the Rayleigh scattering signal, because the received LIDAR signal is a combination of the Doppler-broadened molecular backscatter spectrum and the un-broadened aerosol spectrum[4].

In this study, the Ångström exponent, color ratio, and LIDAR ratio were measured by using two wavelength rotational Raman LIDAR signals to obtain the aerosol size distribution. The backscattering coefficients, which have a close relation to atmospheric aerosol concentration were also calculated. Finally, the cloud and aerosol size characteristics were analyzed by using the Ångström exponent, color ratio, and LIDAR ratio.

\section{METHOD}

In rotational Raman LIDAR, the two return signals can be expressed as Eqs. (1) and (2)[9, 10].

$$
\begin{aligned}
& P_{R}^{\lambda_{1}}(z)=\frac{C_{1}}{z^{2}} O(z) \beta_{R}^{\lambda_{1}} \exp \left\{-2 \int_{0}^{z}\left[\alpha_{m}^{\lambda_{1}}\left(z^{\prime}\right)+\alpha_{a}^{\lambda_{1}}\left(z^{\prime}\right)\right] d z^{\prime}\right\}, \\
& P_{E}^{\lambda_{1}}(z)=\frac{C_{2}}{z^{2}} O(z)\left(\beta_{a}^{\lambda_{1}}+\beta_{m}^{\lambda_{1}}\right) \exp \left\{-2 \int_{0}^{z}\left[\alpha_{m}^{\lambda_{1}}\left(z^{\prime}\right)+\alpha_{a}^{\lambda_{1}}\left(z^{\prime}\right)\right] d z^{\prime}\right\},
\end{aligned}
$$

where $P$ is the LIDAR signal, $\lambda$ is the scattering wavelength, $\beta$ is the backscattering coefficient, $\alpha$ is the extinction coefficient, $O(z)$ is the overlapping function, $z$ is the altitude, $C$ is a constant that is independent of the altitude, and $E, R, a$, and $m$ represent the elastic, rotation, aerosol, and atmospheric molecule, respectively. The aerosol backscattering coefficient can be obtained from these two signals as shown in Eq. (3)[11].

$$
\frac{P_{E}^{\lambda_{1}}(z)}{P_{R}^{\lambda_{1}}(z)}=\frac{C_{2}}{C_{1}} \frac{\beta_{a}^{\lambda_{1}}(z)+\beta_{m}^{\lambda_{1}}(z)}{\beta_{R}^{\lambda_{1}}(z)}=\frac{C_{2}}{C_{1}} \frac{N(z) d \sigma_{m}^{\lambda_{1}} / d \Omega}{N(z) d \sigma_{R}^{\lambda_{1}} / d \Omega}+\frac{C_{2}}{C_{1}} \frac{\beta_{a}^{\lambda_{1}}(z)}{\beta_{R}^{\lambda_{1}}(z)}=\frac{C_{2}}{C_{1}} C_{m / R}+\frac{C_{2}}{C_{1}} \frac{\beta_{a}^{\lambda_{1}}(z)}{\beta_{R}^{\lambda_{1}}(z)}
$$

where $C_{m / R}$ is the ratio of the scattering cross section between the Rayleigh and the total rotational Raman, $N$ is the number density of molecules(oxygen and nitrogen), $\Omega$ is the solid angle, and $\sigma$ is the scattering cross section of the atmospheric molecule. Two unknown values $\left[C_{2} / C_{1} \times C_{m / k}, \frac{\beta_{a}^{\lambda}(z)}{\beta_{m}^{\lambda}(z)}\right]$ can be obtained by using the method of Kim and Cha[11]. The constant $C_{2} / C_{1} \times C_{m / s}$ can be obtained experimentally on a clear day by using a large range of LIDAR signals at a high altitude. And the experimental constant $C_{2} / C_{1}$ can be calculated within statistical errors by using the theoretical scattering cross section of rotational Raman scattering and the elastic scattering of nitrogen and oxygen. Thus the aerosol backscattering value is $\beta_{a}^{\lambda}(z) / \beta_{m}^{\lambda}(z)$ normalized with the molecular rotational backscattering coefficient[11]. The aerosol backscattered color ratio $\left[\mathrm{CR}=\frac{\beta_{a}^{532}(z)}{\beta_{a}^{335}(z)}\right]$ can be obtained from the ratio of the aerosol backscattering coefficients between two wavelengths. The aerosol color ratio value provides good information about the relative size change of the aerosol, which does not directly correspond to the absolute value of the aerosol size[12].

The aerosol extinction coefficient can be obtained from Eq. (1). The aerosol extinction coefficient can be expressed as Eq. (4) from Eq. (1), by substituting $k(z)$ for a constant $C_{1} \times O(z)$.

$$
\alpha_{a}=-\frac{1}{2} \frac{d}{d z}\left(\ln \frac{z^{2} P_{R}}{k(z)}\right)-\alpha_{m},
$$

From Eq. (3), the aerosol Ångström exponent can be obtained. As mentioned above, the two unknown values $\left[C_{2} / C_{1} \times C_{m / k}, \frac{\beta_{a}^{\lambda}(z)}{\beta_{m}^{\lambda}(z)}\right]$ in Eq. (3) can be obtained experimentally. So $\frac{\beta_{a}^{\lambda_{1}}(z)}{\beta_{R}^{\lambda_{1}}(z)}$ can be calculated from the two unknown values. The ratio of backscattering coefficients, $Q(z)=\frac{\beta_{a}^{\lambda_{1}}(z)}{\beta_{R^{\lambda_{1}}}(z)}$, at $\operatorname{two}(355 \mathrm{~nm}$ and $532 \mathrm{~nm})$ wavelengths are given by

$$
\mathrm{P}(\mathrm{z})=\frac{\beta_{a}^{532}(z)}{\beta_{R}^{532}(z)} / \frac{\beta_{a}^{355}(z)}{\beta_{R}^{355}(z)} .
$$

Since $\beta_{R}^{\lambda}=C_{0} \lambda^{-4}$, it can be rewritten as

$$
\mathrm{P}(\mathrm{z})=\frac{\beta_{a}^{532}(z)}{\beta_{a}^{355}(z)} \frac{(355)^{-4}}{(532)^{-4}}
$$

The Ångström exponent $k$, which describes the wavelength dependence of the particle backscattering coefficient, can be expressed by Eq. (7).

$$
\frac{\beta_{a}^{532}(z)}{\beta_{a}^{355}(z)}=\left(\frac{355}{532}\right)^{k}
$$

Consequently, from Eq. (6), (7), the Ångström exponent can be expressed as Eq. (8).

$$
k=\frac{\log (A)}{\log \left(\frac{355}{532}\right)},
$$


where $A$ is $P(z) \times \frac{(532)^{-4}}{(355)^{-4}}$.

\section{EXPERIMENTAL SETUP AND RESULTS}

In this study, the two wavelength Raman LIDAR system was installed by using a $355 \mathrm{~nm}$ and $532 \mathrm{~nm}$ laser beam of a Nd:YAG laser. The pulsed energy of the laser beams were $130 \mathrm{~mJ}$ and $300 \mathrm{~mJ}$ at $355 \mathrm{~nm}$ and $532 \mathrm{~nm}$, respectively. Figure 1 shows a schematic diagram of the installed LIDAR system. To decrease laser beam divergence, a beam expander was used in the transmitting system, which can expand a laser beam by 10 times. The receiving system consisted of 4 channels, namely rotational Raman channels at $355 \mathrm{~nm}$ and $532 \mathrm{~nm}$, and two elastic channels at $355 \mathrm{~nm}$ and $532 \mathrm{~nm}[10,11]$.

Figures 2(a) and 2(b) show the change of aerosol backscattering coefficients measured using the two wavelength LIDAR signals on June 10, 2010 (cloudy day) at different times. In the figures, it can be seen that even though the boundary layer is at the same altitude $(2000 \mathrm{~m})$, the backscattering coefficient changes dramatically from $2.24 \times 10^{-4}$ $\mathrm{m}^{-1}$ to $1.81 \times 10^{-4} \mathrm{~m}^{-1}(355 \mathrm{~nm})$ within the boundary layer. At the other wavelength $(532 \mathrm{~nm})$, the change of the backscattering coefficient with altitude is not the same as that of $355 \mathrm{~nm}$. But the cause of the backscattering coefficient variance is unknown, because the backscattering coefficient is not solely dependent on the aerosol size and concentration. To obtain the quantitative information, the color ratio was calculated at two different times. Figure 2(c) shows the color ratios that have a close relation to the aerosol size distribution. In Fig. 2(c), it can be seen that the aerosol size distribution value decreased from 0.25 to 0.14 and from 0.26 to 0.15 in the boundary layer with the altitude at $21: 50$ and $23: 19[12,15]$. In this case, the color ratios are similar to each other at all altitudes.

Figures 3(a) and 3(b) show the change of the aerosol backscattering coefficients on Dec. 4, 2007 (clear day) at different times. In Figs. 3(a) and 3(b), it can also be seen that even though the boundary layer is the same altitude $(1300 \mathrm{~m})$, the backscattering coefficient changes by a factor of 7 from $3.22 \times 10^{-5} \mathrm{~m}^{-1}$ to $2.15 \times 10^{-4} \mathrm{~m}^{-1}$ (355 nm) within the boundary layer. Figure $3(\mathrm{c})$ shows the change of the color ratio measured at these two different times. At $1000 \mathrm{~m}$ altitude, the color ratio value was 0.83 at $22: 17$, and 1.04 at 23:18, respectively. Compared with Fig. 2(c),

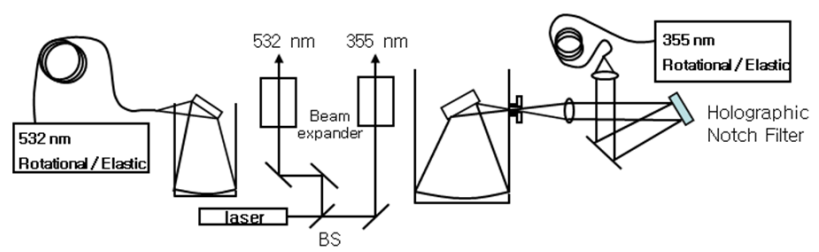

FIG. 1. Schematic diagram of the experimental system. these figures show a strong change in the color ratio within the boundary layer according to the altitude. In particular, the change of color ratio value at the boundary layer $(1300 \mathrm{~m})$ was dramatic even in one hour, even though the change of color ratio value within and above this boundary layer was small. It means that aerosol dynamics usually start at the surface of the boundary[13,

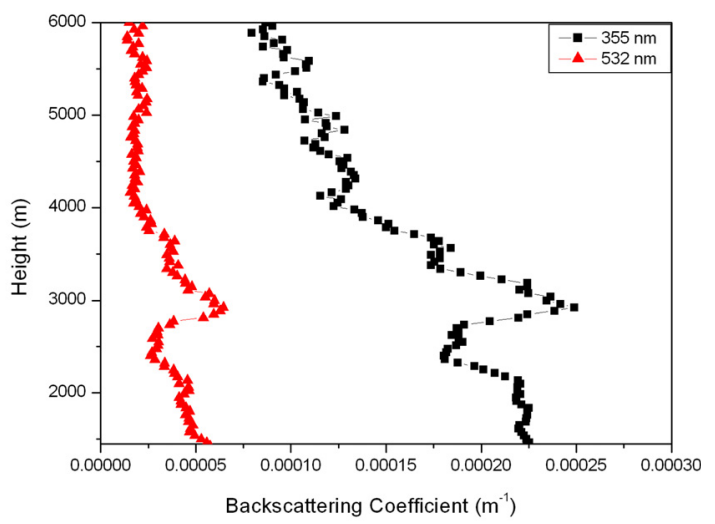

(a)

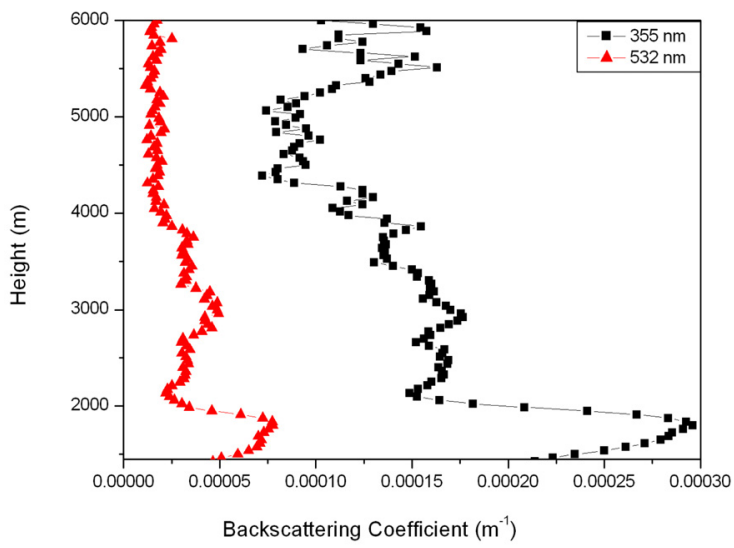

(b)

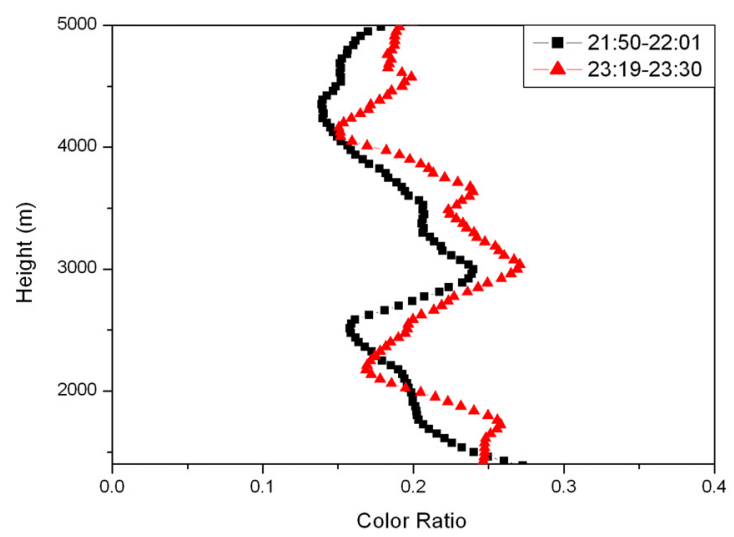

(c)

FIG. 2. The backscattering coefficients and the corresponding color ratio measured on June 10, 2010(cloudy day) at different times; (a) the backscattering coefficients by using two wavelength LIDAR signals at 21:50-22:01 (KST), (b) the backscattering coefficients at 23:19-23:30 (KST), (c) color ratio by using the backscattering coefficients. 


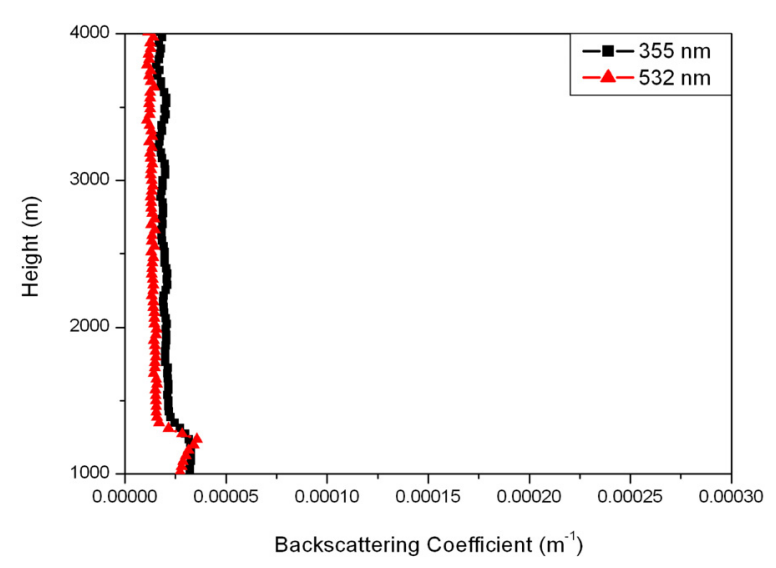

(a)

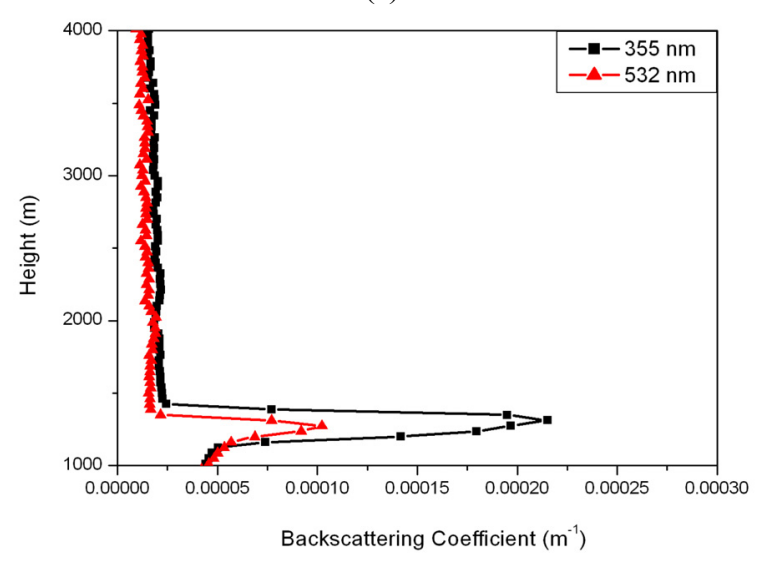

(b)

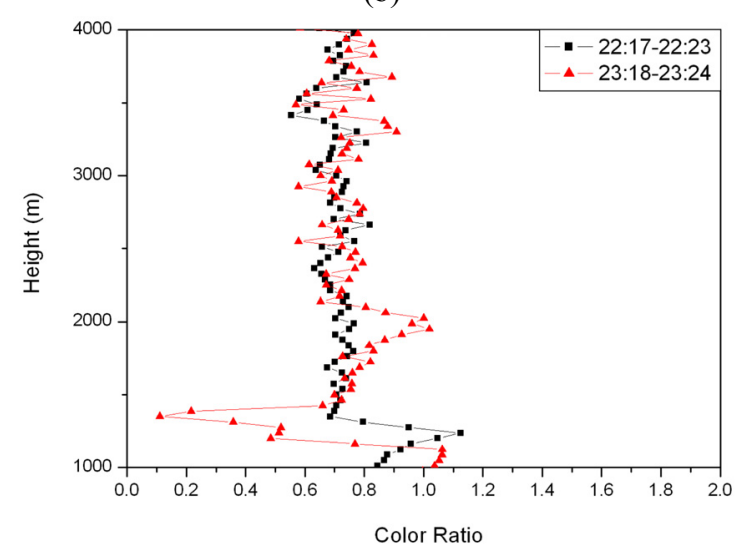

(c)

FIG. 3. The backscattering coefficients and the corresponding color ratio measured on Dec. 4, 2007 (clear day) at different times; (a) the backscattering coefficients at 22:17-22:23 (KST), (b) the backscattering coefficients at 23:18-23:24 (KST), (c) the color ratio by using the backscattering coefficients. It can be seen that the color ratio sharply changed within the boundary layer according to the altitude.

16]. In conclusion, the aerosol color ratio changes within the boundary layer and near the cloud, even in a short time period in this case.

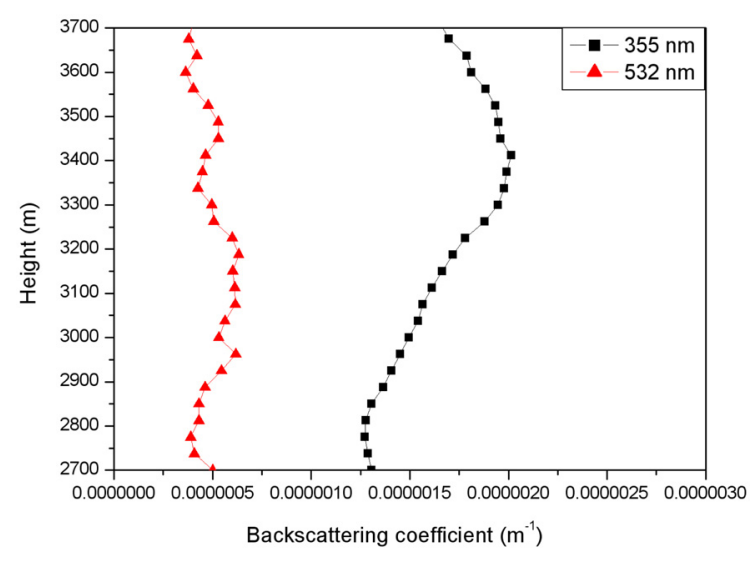

(a)

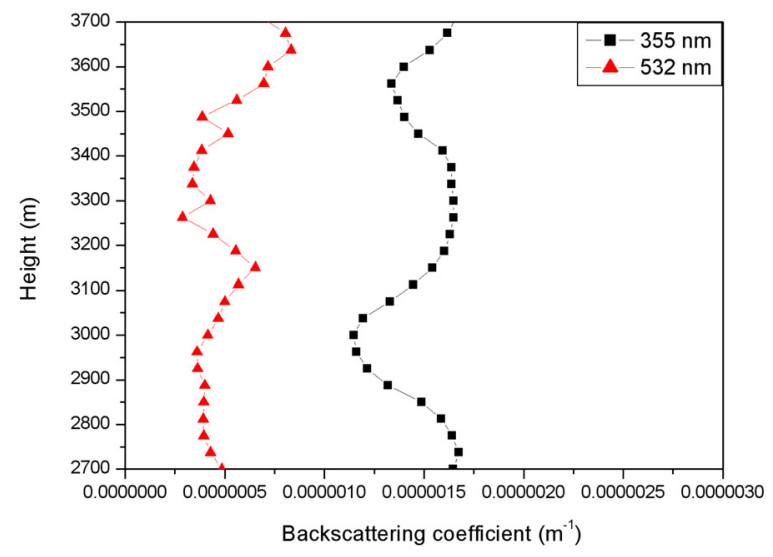

(b)

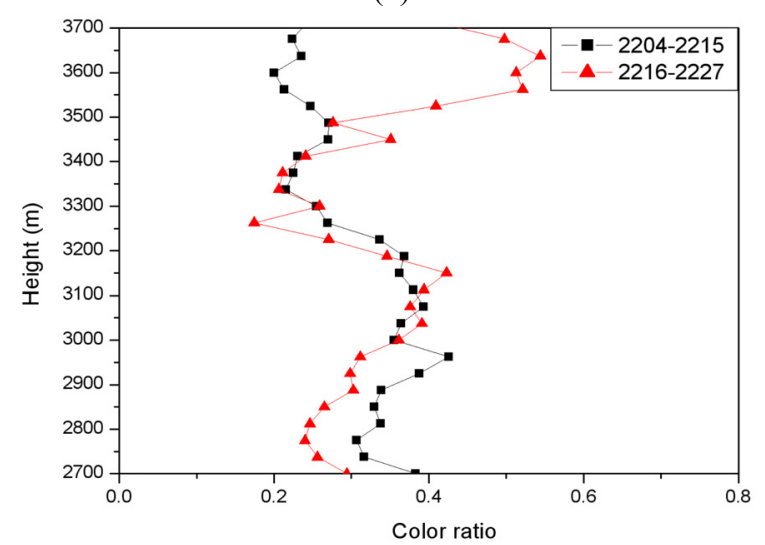

(c)

FIG. 4. The backscattering coefficients and the corresponding color ratio measured on May 30, 2010 (cloudy day) at different times; (a) the backscattering coefficients at 22:04-22:15 (KST), (b) the backscattering coefficients at 22:16-23:27 (KST), (c) the color ratio by using the backscattering coefficients. The change of color ratio value between $3500 \mathrm{~m}$ and $3700 \mathrm{~m}$ was dramatic, even in 11 minutes.

Figures 4(a) and 4(b) show the change of the aerosol backscattering coefficients on May 30, 2010 (cloudy day) at different times. In Fig. 4(a), it can be seen that the 
backscattering coefficient increased from $1.3 \times 10^{-6} \mathrm{~m}^{-1}$ to $2.0 \times 10^{-6} \mathrm{~m}^{-1}$ at $355 \mathrm{~nm}$ between $2700 \mathrm{~m}$ and $3400 \mathrm{~m}$. The backscattering coefficient showed no change at $532 \mathrm{~nm}$ at the same altitudes $(2700-3400 \mathrm{~m})$. Figure $4(\mathrm{~b})$ shows that the backscattering coefficient varied sharply at the same altitudes $(2700-3400 \mathrm{~m})$. On the other wavelength $(532$ $\mathrm{nm}$ ), the change of the backscattering coefficient with altitude was not the same with the change of $355 \mathrm{~nm}$. Figure 4(c) shows the change of the color ratio measured at these two different times. At $2700 \mathrm{~m}$ altitude, the color ratio value was 0.38 at $22: 04$, and 0.29 at $22: 16$, respectively. The average value of the color ratio was 0.23 at 22:04 and 0.45 at $22: 16$ between $3500 \mathrm{~m}$ and $3700 \mathrm{~m}$. In particular, the change of color ratio value between 3500 $\mathrm{m}$ and $3700 \mathrm{~m}$ was dramatic, even in 11 minutes. This figure shows that the aerosol concentration and aerosol size distribution change, even in such a short time period.

Figure 5 shows the change of the Ångström exponent, the color ratio, the Ångström exponent versus color ratio, and the LIDAR ratio at $355 \mathrm{~nm}$ and $532 \mathrm{~nm}$ measured on
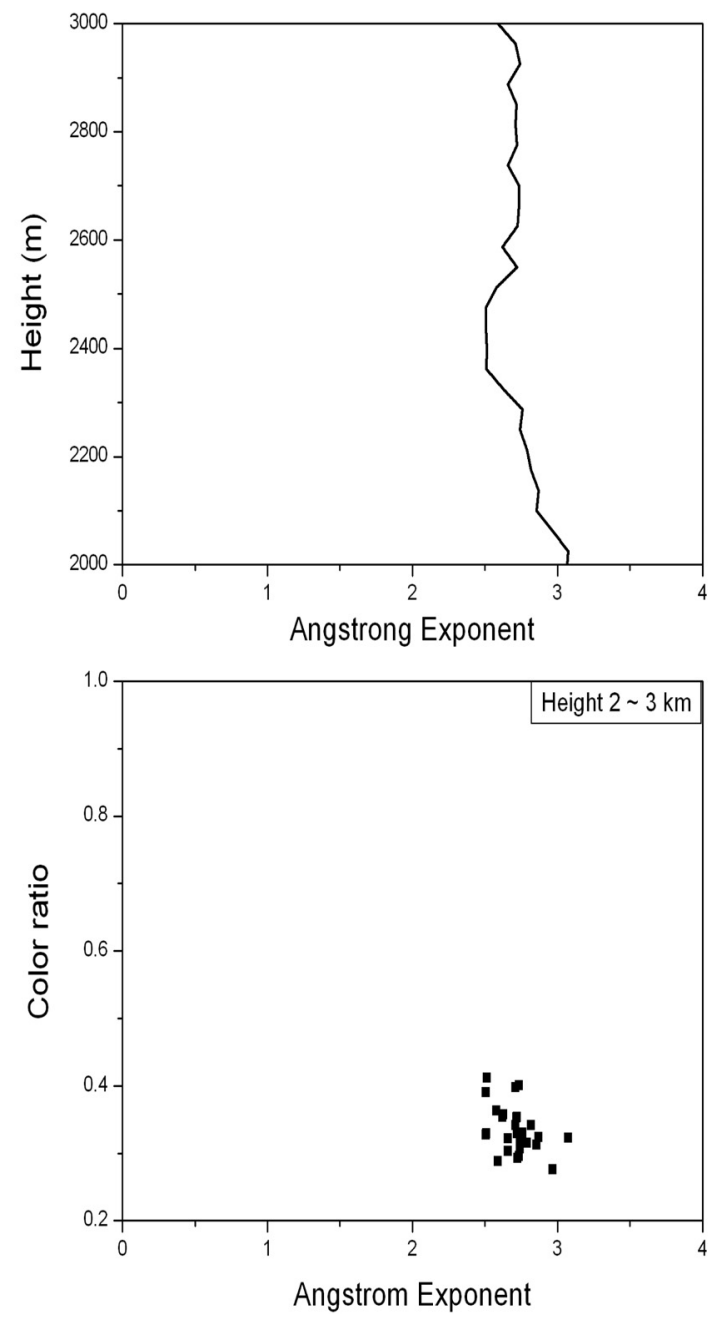

May 31, 2010 (cloudy day). In Fig. 5, it can be seen that the Ångström exponent changed from 2.5 to 3.1 and the color ratio changed from 0.28 to 0.42 at altitudes between $2000 \mathrm{~m}$ and $3000 \mathrm{~m}$. There were no noticeable changes in the Ångström exponent and color ratio. So, a clear relationship between the Ångström exponent and color ratio is not known. The average value of the LIDAR ratio was $66.9 \mathrm{sr}$ at $355 \mathrm{~nm}$ and $32.6 \mathrm{sr}$ at $532 \mathrm{~nm}$ at the same altitude $(2000-3000 \mathrm{~m})$. These values are thought to be reasonable also by other studies[14, 17].

Figure 6 shows the change of the Angström exponent, the color ratio, the Ångström exponent versus color ratio, and the LIDAR ratio at $355 \mathrm{~nm}$ measured on June 11, 2010 (rainy day). It can be seen that the Ångström exponent increased from 1.2 to 2.7 and the color ratio decreased from 0.64 to 0.32 at altitudes between $2000 \mathrm{~m}$ and 3000 $\mathrm{m}$. These values are also thought to be reasonable also by many other studies[3, 12, 15]. It can be seen that the Ångström exponent and color ratio varied sharply with the corresponding altitudes when we comparing Fig. 5 with
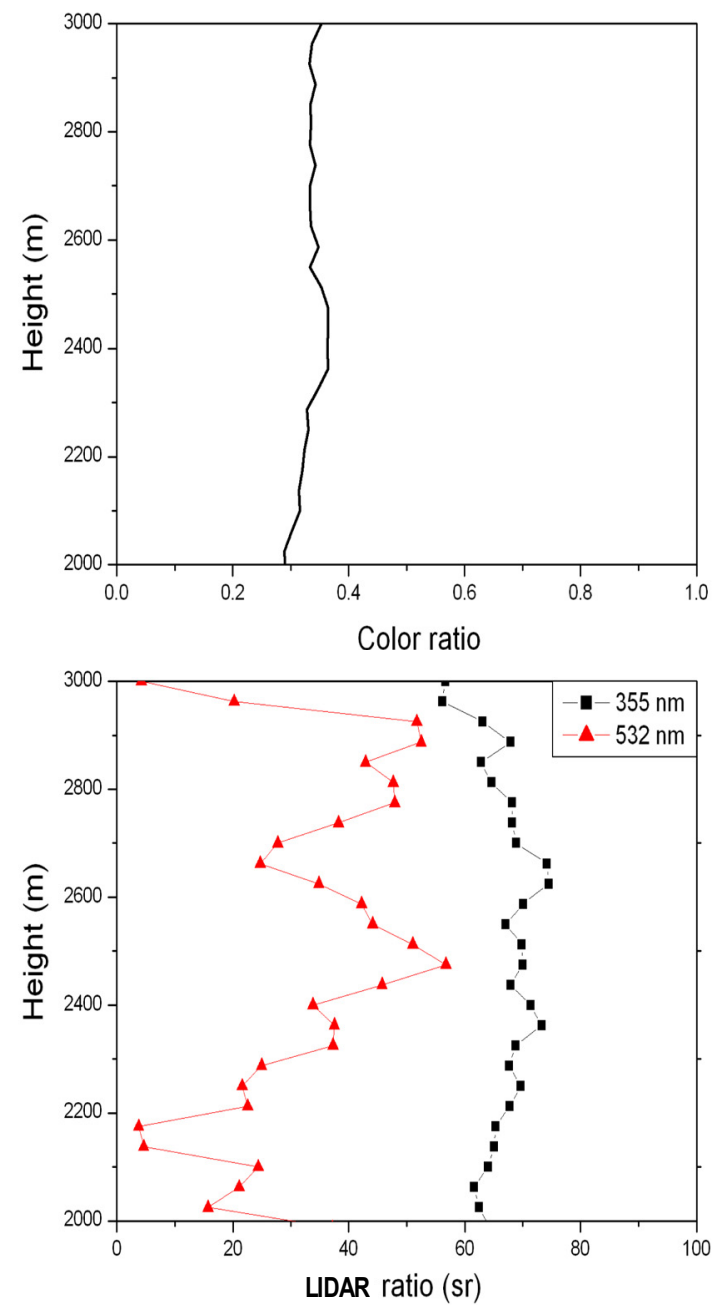

FIG. 5. The Ångström exponent, the color ratio, the Ångström exponent versus color ratio, and the LIDAR ratio at $355 \mathrm{~nm}$ and $532 \mathrm{~nm}$ measured on May 31, 2010 (cloudy day) at 21:58-22:04 (KST). 

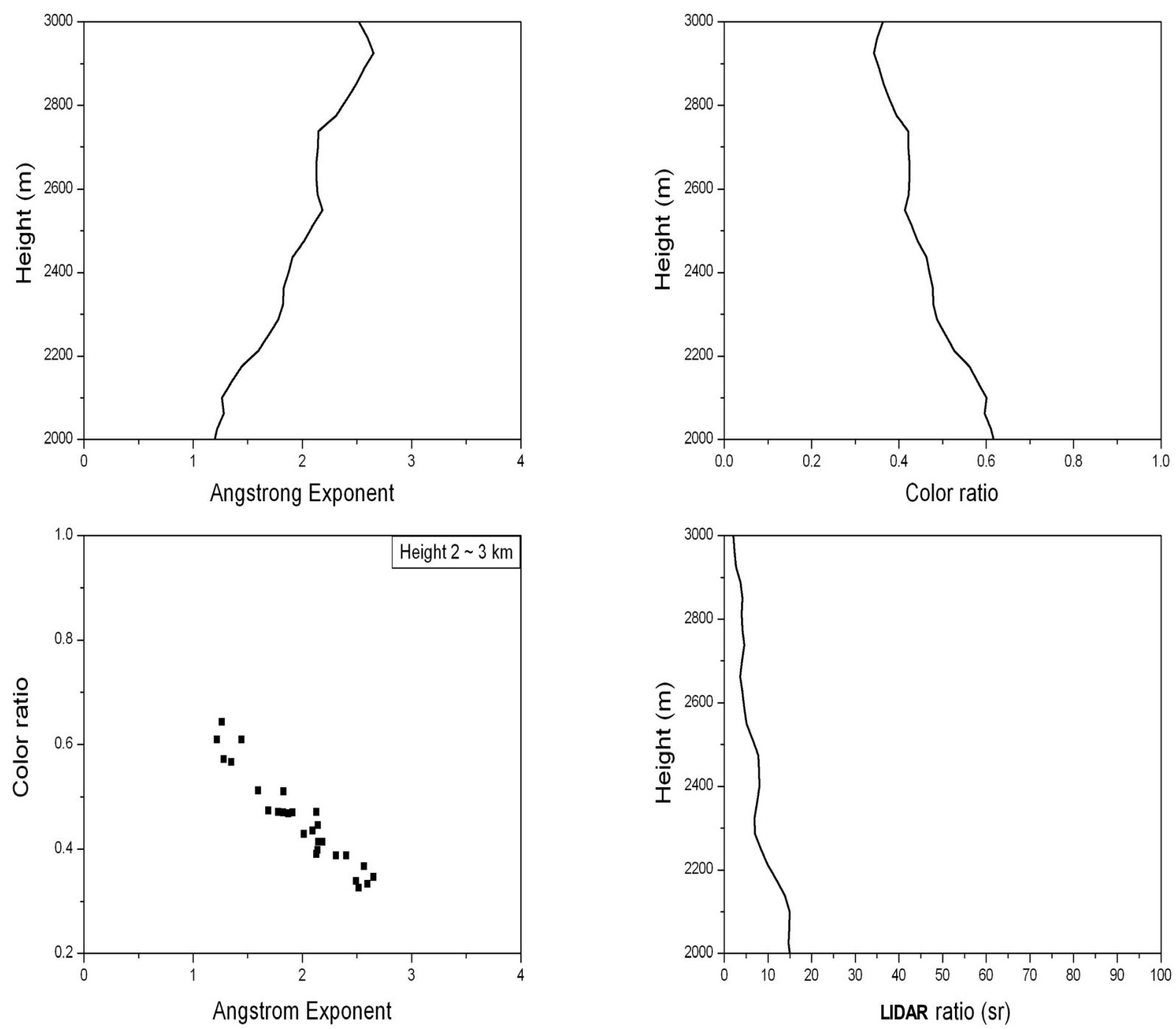

FIG. 6. The Ångström exponent, the color ratio, the Ångström exponent versus color ratio, and the LIDAR ratio at $355 \mathrm{~nm}$ measured on June 11, 2010 (rainy day) at 24:04-24:10 (KST). A change of Angström exponent and color ratio could be detected when the altitude changed from $2000 \mathrm{~m}$ to $3000 \mathrm{~m}$. So an inverse relation can be seen between the color ratio and Ångström exponent.

Fig. 6. Also, in Fig. 6, an inverse relation can be seen between the color ratio and Ångström exponent, as was mentioned in Eq. 7. The average value of the LIDAR ratio depends on the weather conditions $[14,17]$ it has changed from $60 \mathrm{sr}$ (Fig. 5) to $7.0 \mathrm{sr}$ (Fig. 6) at $355 \mathrm{~nm}$ at the same altitude $(2000-3000 \mathrm{~m})$. On a rainy day, a change of Ångström exponent and color ratio could be detected when the altitude changed from $2000 \mathrm{~m}$ to $3000 \mathrm{~m}$. These changes according to altitude come from the change of aerosol size because these two parameters, the Ångström exponent and color ratio, simultaneously indicate an increase of aerosol size as indicated in the introduction. That is to say, the Ångström exponent $k$ value is 4 for molecules and varies between 0 and 2 for particles[3]. This means that the aerosol size increases when the altitude approaches to the cloud or the humidity increases due to the inverse relation of the color ratio and Ångström exponent[12]. It is certain that these aerosol size changes on a rainy day come from the change of humidity, because rainfall was observed 2 minutes after this measurement. From the experimental results, the color ratio, LIDAR ratio, and Ångström exponent can give information about the relative size change of an aerosol.

\section{DISCUSSION AND CONCLUSION}

In conclusion, a two wavelength rotational Raman LIDAR system was installed that can measure aerosol parameters. The spatial/temporal aerosol extinction coefficient, color ratio, LIDAR ratio, and Ångström exponent was measured without any assumption by using two wavelength rotational Raman LIDAR signals. An inverse relation between the color ratio and Angström exponent was observed, as was mentioned in Eq. 7. This means that the Ångström exponent 
has an inverse relationship to the particle size of the aerosol and the color ratio is linearly dependent on the aerosol size. To measure the aerosol size distribution more correctly, the backscattering and extinction coefficient cannot give any information, measurement of the several parameters (color ratio, LIDAR ratio, and Ångström exponent) can provide much better results than one parameter measurement. By using these several parameters, a difference in the aerosol concentration and aerosol size distribution in the boundary layer can be observed. The boundary layer is physically very important for heat transfer, free convection currents and aerodynamics etc, but there is not enough data when using only the extinction and backscattering coefficient of the boundary layer and an aerosol dynamic study which is dependent in a complex way on the meteorological parameters. In the future, the change in the boundary layer will be measured more quickly and correctly.

\section{ACKNOWLEDGMENT}

This work was funded by the Korea Meteorological Administration Research and Development Program under the Grant CATER 2006-3101.

\section{REFERENCES}

1. K. H. Lee, J. E. Kim, Y. J. Kim, J. Kim, and W. Hoyningen-Huene, "Impact of the smoke aerosol from Russian forest fires on the atmospheric environment over Korea during May 2003," Atmos. Environ. 39, 85-99 (2005).

2. W. N. Chen, S. Y. Chang, C. C. K. Chou, and T. K. Chen, "Total scatter-to-backscatter ratio of aerosol derived from aerosol size distribution measurement," Int. J. Environment and Pollution 37, 45-54 (2009).

3. P. B. Russell, R. W. Bergstrom, Y. Shinoznka, A. D. Clarke, P. F. Decarlo, J. L. Jimenez, J. M. Livingston, J. Redemann, B. Holben, O. Dubovic, and A. Strawa, "Absorption Ángström exponent in AERONET and related data as an indicator of aerosol composition," Atmos. Chem. Phys. Discuss. 9, 21785-21817 (2009).

4. C. Y. She, R. J. Alvarez II, L. M. Caldwell, and D. A. Krueger, "High-spectral-resolution Rayleigh-Mie LIDAR measurement of aerosol in atmospheric profiles," Opt. Lett. 17, 541-543 (1992).

5. V. Rizi, M. Larlori, G. Rocci, and G. Visconti, "Raman LIDAR observations of cloud liquid water," Appl. Opt. 43, 6440-6453 (2004).

6. A. Ansmann, U. Wandinger, M. Riebesell, C. Weitkamp, and W. Michaelis, "Independent measurement of extinction and backscatter profiles in cirrus clouds by using a combined Raman elastic-backscatter LIDAR,” Appl. Opt. 31, 7113-7131 (1992).

7. A. Angström, "On the atmospheric transmission of sun radiation and on dust in the atmosphere," Geogr. Ann. 11, 156-166 (1929).

8. D. G. Kaskaoutis and H. D. Kambezidis, "Comparison of the Angström parameters retrieval in different spectral ranges with the use of different techniques," Meteorol. Atmos. Phys. 99, 233-246 (2008).

9. D. Kim, S. Park, H. Cha, J. Zhou, and W. Zhang, "New multi-quantum number rotational Raman LIDAR for obtaining temperature and aerosol extinction and backscattering scattering coefficients," Appl. Phys. B 82, 1-4 (2006).

10. D. Kim and H. Cha, "Rotational Raman LIDAR for obtaining aerosol scattering coefficients," Opt. Lett. 30, 1728-1730 (2005).

11. D. Kim and H. Cha, "Rotational Raman LIDAR: design and performance test of meteorological parameters(Aerosol backscattering coefficients and temperature)," J. Korean Phys. Soc. 51, 352-357 (2007).

12. D. Kim and H. Cha, "Suggestion for qualitative LIDAR identification of different types of aerosol using the two wavelength rotational Raman and elastic LIDAR," Opt. Lett. 31, 2915-2917 (2006).

13. H. Blasius, "Das Äehnlichkeitsgesetz bei Reibungsvorgänegen," Z. Ver. Dtsch. Ing. 16, 639-643 (1912).

14. Y. M. Noh, Y. J. Kim, B. C. Choi, and T. Murayama, "Aerosol LIDAR ratio characteristics measured by a multi-wavelength Raman LIDAR system at Anmyeon Island, Korea," Atmos. Res. 86, 76-87 (2007).

15. A. H. Omar and T. Babakaeva, "Aerosol optical properties derived from LIDAR observations using cluster analysis," IEEE Intern. Geo. Rem. Sens. 3, 2212-2215 (2004).

16. L. Prandlt, "Über Flüssigkeitsbewegung bei sehr Kleiner Reibung," Verh. III. Intern. Math. Kongr. Heidelberg, 484-491 (1904).

17. A. Ansmann and D. Müller, "LIDAR and atmosphere aerosol particles," Springer 102, 112-117 (2005). 